\title{
Global atmospheric response to specific linear combinations of the main SST modes. Part I: numerical experiments and preliminary results
}

\author{
S. Trzaska, V. Moron, B. Fontaine \\ Centre de Recherches de Climatologie, Université de Bourgogne, 6, bd. Gabriel, 2100 Dijon, France
}

Received: 13 May 1995/Revised: 1 April 1996/Accepted: 11 April 1996

\begin{abstract}
This article investigates through numerical experiments the controversial question of the impact of El Nino-Southern Oscillation (ENSO) phenomena on climate according to large-scale and regional-scale interhemispheric thermal contrast. Eight experiments (two considering only inversed Atlantic thermal anomalies and six combining ENSO warm phase with large-scale interhemispheric contrast and Atlantic anomaly patterns) were performed with the Météo-France atmospheric general circulation model. The definition of boundary conditions from observed composites and principal components is presented and preliminary results concerning the month of August, especially over West Africa and the equatorial Atlantic are discussed. Results are coherent with observations and show that interhemispheric and regional scale sea-surface-temperature anomaly (SST) patterns could significantly modulate the impact of ENSO phenomena: the impact of warm-phase ENSO, relative to the atmospheric model intercomparison project (AMIP) climatology, seems stronger when embedded in global and regional SSTA patterns representative of the post-1970 conditions [i.e. with temperatures warmer (colder) than the long-term mean in the southern hemisphere (northern hemisphere)]. Atlantic SSTAs may also play a significant role.
\end{abstract}

\section{Introduction}

Numerous diagnostic investigations have shown that rainfall variability at monthly and seasonal timescales in the tropics is mainly linked to global sea-surface-temperature anomaly (SSTA) fields. Such relationships have not only been documented for the global tropics (Ropelewski and Halpert, 1987; Shukla and Fennessy, 1988) but also for the Asian-Australian monsoon system as a whole

Correspondence to: S. Trzaska
(Rasmusson and Carpenter, 1982) and over specific areas like India (Shukla, 1987), Indonesia (Nicholls, 1984) and East Africa (Hastenrath, 1991; Camberlin, 1995). It appears that the convergence at global scale is strongly linked to SSTA fields (Gill, 1980) which may be considered as the major forcing of tropical atmospheric variability beyond monthly scales (Palmer and Anderson, 1994; Rowell et al., 1995). Since SST maxima are regions of significant deep convection systems associated with latent heat release in middle and upper troposphere, they fuel the global atmospheric engine, leading to remote atmospheric response to initial SSTAs.

The first mode of large-scale climatic variability partly controlling the rainfall anomaly patterns is the El NiñoSouthern Oscillation (ENSO) (Rasmusson and Carpenter, 1982; Ropelewski and Halpert, 1987). Its impact is strongest on the Indo-Pacific domain, but it still controls rainfall fluctuations in the West African and American monsoon systems, even though in these regions the tropical Atlantic appears to be more implicated (Hastenrath and Covey, 1978; Ropelewski and Halpert, 1987). On the other hand, Janicot et al. (1996) demonstrated that relationships between the Southern-Oscillation Index (SOI) and West African rainfall anomalies are unstable between 1945 and 1993. Mixing of different influences seems strong around the tropical Atlantic.

A number of studies concerning rainfall variability over the African Sahel (Tanaka et al., 1975; Lamb, 1978a, b) and the Nordeste region of Brazil (Markham and McLain, 1977; Hastenrath and Heller, 1977; Ward and Folland, 1991) have shown that rainfall variability is related to specific meridional SST patterns. Further investigation results [Lamb (1978a, b), Hastenrath (1984), Janicot (1992), Fontaine and Bigot (1993) for the Sahel; Moura and Shukla (1981), Roucou et al. (1996) for Brazil] showed that rains in Sahel (resp. Brazil) are closely associated with the most northern (resp. southern) position of the Intertropical Convergence Zone (ITCZ). Basically, the warmer- (resp. colder-) than-normal SST in the northern (southern) parts of the tropical Atlantic lead to a more northward ITCZ position inducing less (more) seasonal 
rainfall in Nordeste in March, and in Sahel in August. Physical links between Sahelian rainfall and Atlantic SSTA during northern summer have been studied particularly by Druyan (1991), Palmer et al. (1992), Ward et al. (1993), Rowell et al. (1995) and Diedhiou and Mahfouf (1996). So around the Atlantic, ENSO phenomena seem to be mixed with other events of regional scale, such as the dipole between northern-tropical and equatorial Atlantic, see Lamb (1978a, b), Lough (1986) and Rowell et al. (1995), or global scale, as the interhemispheric gradient between the northern and southern hemispheres which reverses near 1965-1970, see Folland et al. (1986) and Parker et al. (1994). More importantly, all these climatic signals do not operate at the same timescales, since ENSO variability is concentrated between 2 and 6 years, whereas interhemispheric and regional dipole patterns have strong decadal and longer variability (Folland et al., 1986; Kawamura, 1994; Shinoda and Kawamura, 1994; Mehta and Delworth, 1995). Thus, relationships between SSTA and seasonal rainfall cannot be considered without taking into account both their teleconnexions and their own time evolutions (Palmer, 1986; Rowell et al., 1995).

This question is investigated by considering the impact of various regional or global interhemispheric SSTA patterns on ENSO forcing on the global climatic system. We focus our study on the tropical Atlantic area where ENSO impact is weakest in the tropical domain, and where interdecadal variance seems the most represented. The background of our study is diagnostic; it consists in computing the main orthogonal modes of SSTA variability to define basic surface-temperature patterns and their time evolutions on the period 1950-1990 (Sect. 2). Linear combinations of these modes define fields which objectively document recurrent and significant SSTA patterns (Sect. 3). This method takes into account both decadal changes and SSTA teleconnexions between the basins. Sensitivity experiments are then performed by prescribing these fields as boundary conditions in an atmospheric general-circulation model (AGCM). Numerical integrations have been performed on a realistic version of the Arpege-Climat AGCM developed by Météo-France (Déqué et al., 1994) and these are briefly presented in Sect. 3. Preliminary results are presented (Sect. 4) and discussed (Sect. 5) in terms of monthly anomalies for some selected fields.

\section{SST data and the main modes of variability}

SST data were extracted from the Monthly Observed Sea Surface Temperatures (MOHSST) version 4 dataset compiled at the UKMO (Bottomley et al., 1980) and recently studied by Folland et al. (1993), Kawamura (1994) and Moron et al. (1995a). This dataset is available on a $5^{\circ}$ squared grid at monthly scale from 1856 . Systematic biases in SST data are stronger before the Second World War, when temperature measurements were made using uninsulated or poorly insulated buckets, than after it, when engine-intake measurements became predominant. Even if large bias is corrected in the MOHSST4, the post-1950 period is more homogenous than the previous period (Bottomley et al., 1990). A smoothed version is used for increasing the global climatic signal-to-noise ratio. First, if a value differed by more than $1.5^{\circ} \mathrm{C}$ from its eight surrounding areas, it is replaced by the average. Second, each monthly value is replaced by the running 3-month average (e.g. August 1970 is the average of JulySeptember 1970). Note that the spatial patterns of each mode are very similar to those directly obtained from raw data. Each square was weighted by the cosine of the latitude in order to take into account the sphericity of the earth.

Simple composite analyses of ENSO events on the two half-periods on each side of 1970 clearly reveal changes in the Atlantic basin, but also over the Indian Ocean (Fig. 1a, b). ENSO events before 1970 are characterized by warm anomalies in the North Atlantic, mainly in the Caribbean, whereas cold anomalies are located in the South Atlantic and over the south-western parts of the Indian Ocean (Fig. 1a). This situation reverses after 1970 (Fig. 1b) with large warm anomalies over the western, and central Indian Ocean and South Atlantic, except in the vicinity of the equatorial upwelling and in the North Atlantic. ENSO patterns differ also in the Pacific, the post-1970 period showing a stronger gradient between the eastern and central tropical Pacific on one hand, and the rest of the basin on the other. This indicates the importance of the decadal-scale variability, often observed in the North Atlantic with a change near 1970 (see for example, Deser and Blackmon, 1993; Kushnir, 1994), but also present at a more global scale (Folland et al., 1986). ENSO phenomena are also characterized by an increased intensity of warm events and the scarcity of cold events after 1976-77 (Wang and Ropelewski, 1995).

The covariability of these anomaly fields can be easily synthetized through principal component analysis (PCA), extensively presented in Richman (1986). A rotated PCA with a varimax criterion was hence performed on monthly normalized (after removing the seasonal cycle) SSTA values on the period 1950-1990, after having determined

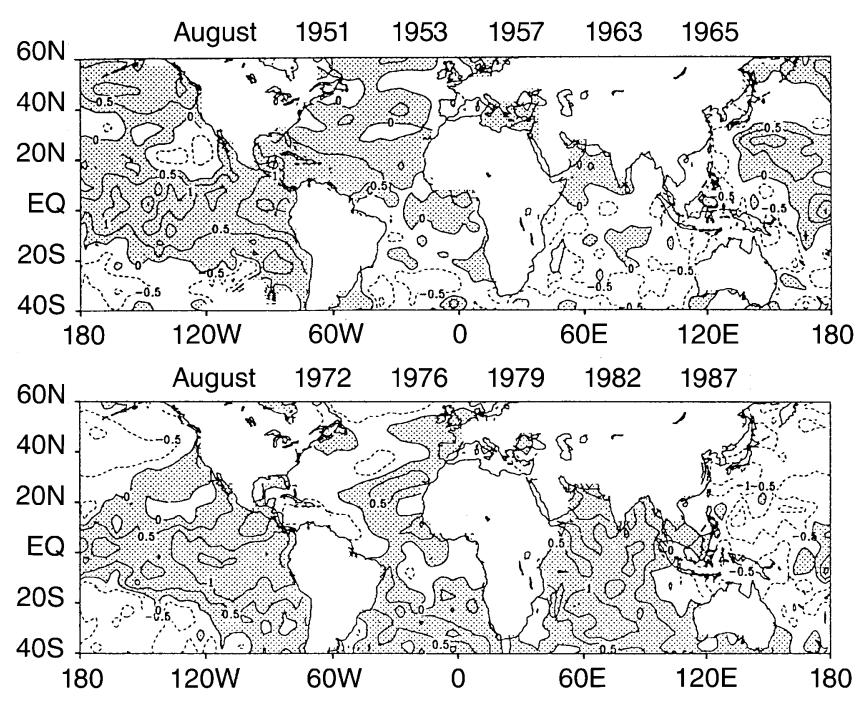

Fig. 1. Composite SSTAs (relative to the 1951-1990 mean) during ENSO warm events in August. Positive (negative) anomaly areas in grey (white) and solid (dashed) lines every $0.5^{\circ} \mathrm{C}$ 
the number of rotated principal components (PCs) by a scree test, namely eleven (O'Lenic and Livezey, 1988). However, to give more accuracy and stability to the results, other possible solutions were tested: it appeared that they did not change the patterns of the four first PCs (Fig. 2) which are also similar to those of Kawamura (1994).

The first PC (10.2\% of total variance) depicts a global tropical wide mode (GTm, Fig. 2a) clearly dominated by an ENSO-like signal with strong positive loadings in the East and Central Pacific, and over the western parts of the Indian Ocean. The second (5.24\%) displays a bipolar structure over the North Atlantic (NAm, Fig. 2b) with rather strong positive loadings in the Central Atlantic and on the tropical side of the Azores anticyclonic circulation. It also exhibits positive loadings in the Northeast Pacific. The third mode $(5.21 \%)$ is characterized by a global out-of-phase signal opposing the northern extratropics to the South Atlantic and Southwestern Indian Ocean. It is rather an extra-tropical mode (GEm, Fig. 2c) whose loadings are strong in the southern Indian and
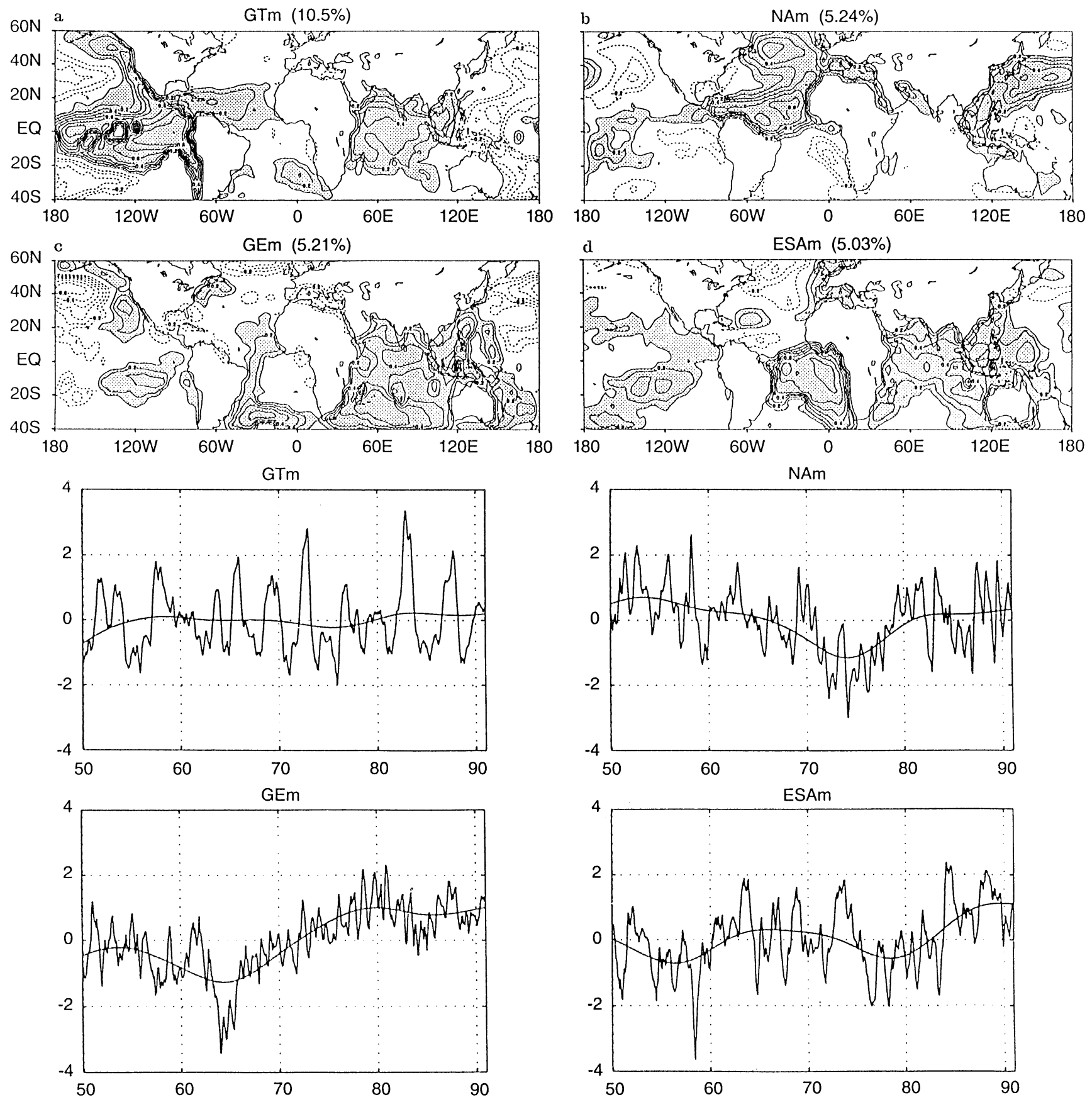

Fig. 2a-d. Loading patterns and time-series of the first four SSTA modes obtained from a Varimax Rotated Principal Component Analysis performed on the period January 1950 to December 1990. Grey (white) areas and solid (dashed) lines display positive (negative)

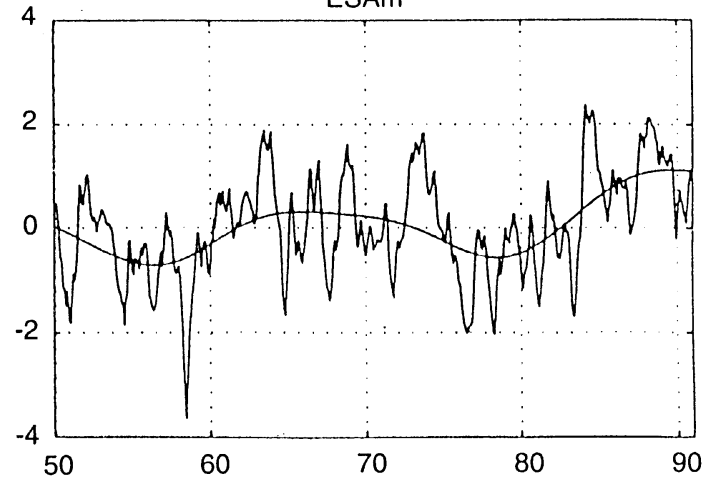

linear correlation coefficients every 0.1. Explained variance: a GTm $(10.2 \%)$, b NAm $(5.21 \%)$, c GEm (5.21\%), d ESAm (5.03\%). Relative time-series with superimposed low-pass filtered curve (period $>7$ years) 
Atlantic Oceans. The fourth mode $(5.03 \%)$ takes into account the variability in the equatorial and southern Atlantic (ESAm, Fig. 2d).

These four modes do not exhibit the same time evolution over the 41-year period (Fig. 2). Quasi-regular oscillations, with a main periodicity of 4 to 5 years, occur for GTm, whereas the three other modes have time evolutions reflecting a stronger weight of decadal-scale fluctuations. This is particularly true for GEm, marked by a slow increase from 1965 to the 1970s and 1980s, and to some extent for the two Atlantic modes, out-of-phase at decadal scale [see the low-pass (period $>7$ years) filtered curve]. Note that the variance explained by these two modes (about $10 \%$ ) equals that due to the sole GTm, and that the additional effect of GEm tends to generate strong meridional interhemispheric gradients over the global ocean. We hypothesize that these decadal changes can significantly modify the impact of ENSO forcing (of interannual timescale) on multidecadal periods, in particular in the vicinity of the Atlantic and Indian basins. In order to test the influence of the Atlantic and Indian-Ocean SSTA, several numerical experiments were performed.

\section{Definition of the experiments}

AGCMs provide an interesting opportunity to investigate different schemes of climate forcing by variable surface conditions. At the interannual scale, SSTs seem to remain dominant, forcing more strongly than biosphere-atmosphere interaction and beyond the internal variability of the atmosphere (Rowell et al., 1995). As the ocean response to the atmospheric changes is very slow compared to atmospheric timescale, oceanic surface temperature can be considered as steady-state boundary conditions for the atmosphere, and quasi-constant if integration time is short relative to the basic memory of the upper ocean. Numerical integrations actually performed were short
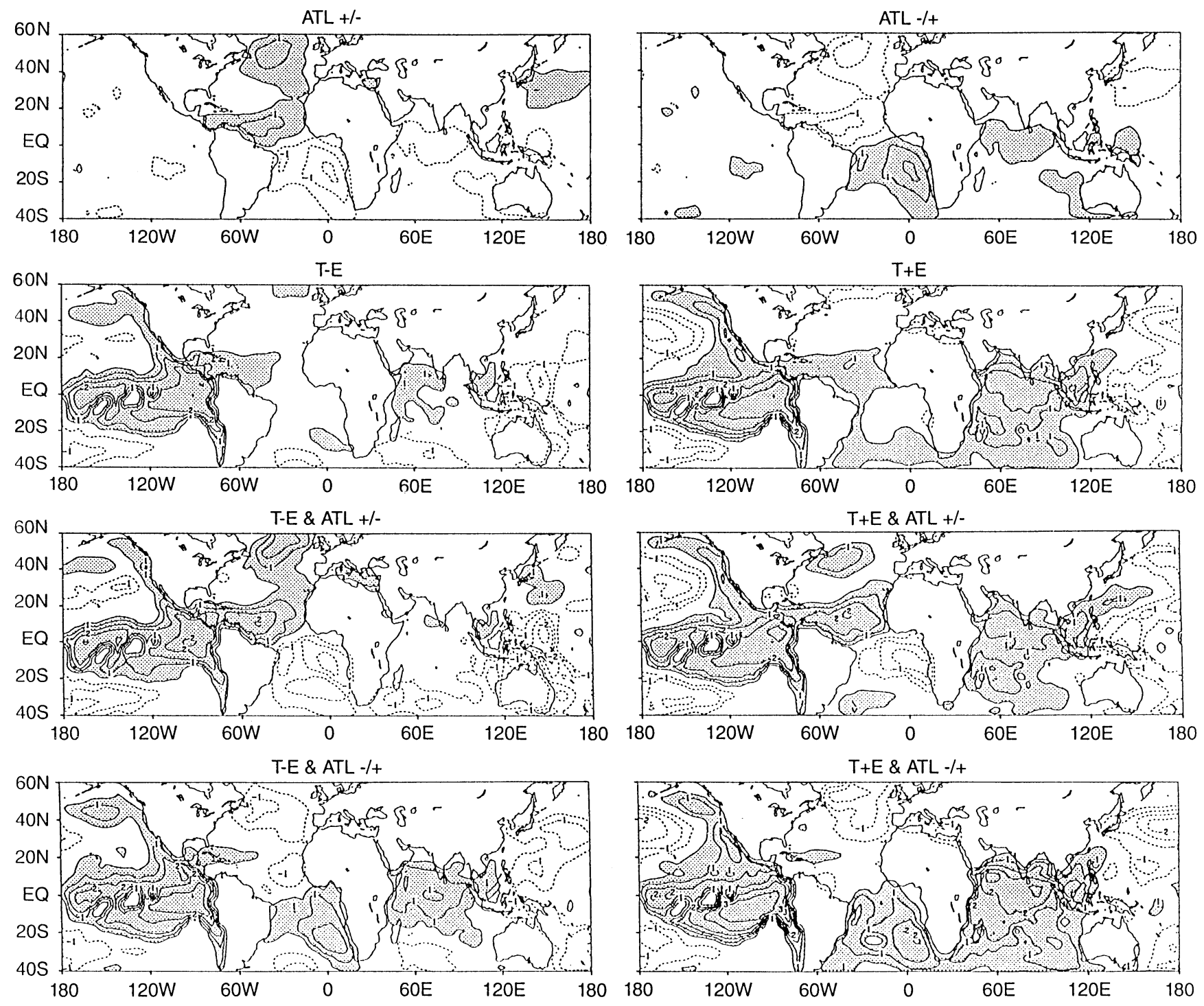

Fig. 3. SSTAs fields (in ${ }^{\circ} \mathrm{C}$ ) used as boundary conditions in the eight numerical experiments (positive anomalies warmer than $0.5^{\circ} \mathrm{C}$

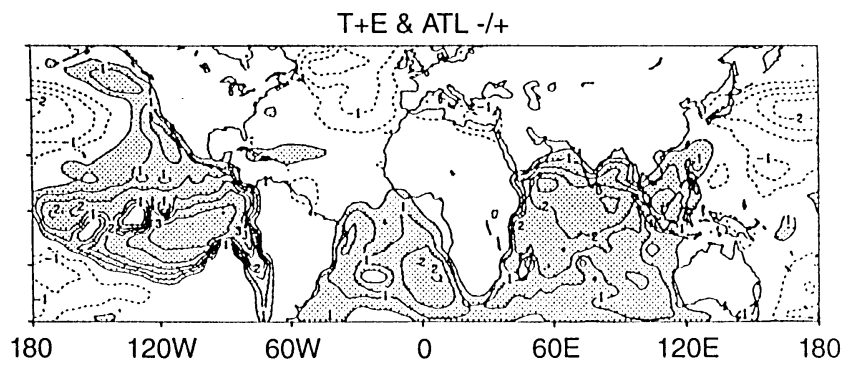

are shaded in grey; negative anomalies colder than $-0.1^{\circ} \mathrm{C}$ in white). Isolines every $0.5^{\circ} \mathrm{C}$ 
enough, as they focussed on the northern-hemisphere monsoon peak which occurs in August.

Eight different SSTA patterns were defined by linearly combining the four PCs described in Sect. 2 (Fig. 3).

- Two of them concern only the Atlantic modes in order to document locally the reversing of the Atlantic meridional thermal gradient:

$$
\begin{aligned}
& -\mathrm{ATL}+/-=(\mathrm{NAm}-\mathrm{ESAm}) \times \mathrm{c} \\
& -\mathrm{ATL}-/+=(-\mathrm{NAm}+\mathrm{ESAm}) \times \mathrm{c}
\end{aligned}
$$

- The next two deal only with global modes and reflect the mutual influence of the extratropical mode and the ENSO-like mode:

$$
\begin{aligned}
& -\mathrm{T}-\mathrm{E}=(2 \times \mathrm{GTm}-\mathrm{GEm}) \times \mathrm{c} \\
& -\mathrm{T}+\mathrm{E}=(2 \times \mathrm{GTm}+\mathrm{GEm}) \times \mathrm{c}
\end{aligned}
$$

- Four patterns document the basic combinations between global and Atlantic modes and take into account simultanously the reverse of the Atlantic gradient and the changes in the extratropical mode:

$$
\begin{aligned}
& -\mathrm{T}-\mathrm{E} \& \mathrm{ATL}+/-=(2 \times \mathrm{GTm}-\mathrm{GEm}+\mathrm{NAm} \\
& -\mathrm{ESAm}) \times \mathrm{c} \quad \text { (Fig. 3e), } \\
& -\mathrm{T}-\mathrm{E} \& \mathrm{ATL}-/+=(2 \times \mathrm{GTm}-\mathrm{GEm}-\mathrm{NAm} \\
& + \text { ESAm }) \times \mathrm{c} \quad \text { (Fig. 3f), } \\
& -\mathrm{T}+\mathrm{E} \& \mathrm{ATL}+/-=(2 \times \mathrm{GTm}+\mathrm{GEm}+\mathrm{NAm} \\
& -\mathrm{ESAm}) \times \mathrm{c} \quad \text { (Fig. 3g), } \\
& -\mathrm{T}+\mathrm{E} \& \mathrm{ATL}-/+=(2 \times \mathrm{GTm}+\mathrm{GEm}-\mathrm{NAm} \\
& +\mathrm{ESAm}) \times \mathrm{c}
\end{aligned}
$$

The factor 2 in front of the GTm refers to the double variance percentage explained by this mode and the factor $\mathrm{c}$ is a dimensioned constant to convert the standard deviation fields into SSTA fields. This constant equals $1.5^{\circ} \mathrm{C}$, in order to define realistic anomalies (i.e. maxima of about $2{ }^{\circ} \mathrm{C}$ in the Atlantic and $3.5^{\circ} \mathrm{C}$ in the Pacific Ocean)

Note that the main changes provided by the increase in ETm anomalies concern the Indian Ocean, which records strong positive anomalies (Fig. $3 \mathrm{~d}, \mathrm{f}, \mathrm{h}$ to be compared with Fig. 3c, e, g) reflecting the changes mentioned in Sect. 2. The reversing of the Atlantic gradient, when combined with global anomalies, leads also to strong positive anomalies in the Indian Ocean (Fig. 3g, h compared with Fig. 3e, f) due to anomalies in the Indian Ocean appearing in so-called Atlantic modes.

These eight anomaly fields were then added to the mean global surface temperature fields used as boundary conditions by an AGCM. We actually used the ARPEGEClimat AGCM version 1.1 developed by CNRM (Centre National de Recherches Météorologiques at MétéoFrance, Toulouse). This is a spectral AGCM with a 30layer vertical resolution. Its physical parametrization includes diurnally and seasonally varying radiation, horizontal and vertical diffusion, mass-flux convection scheme and hydrological cycle, a realistic soil-vegetation scheme, gravity wave drag, mesospheric drag and photochemical parametrization of ozone (for more details see Déqué et al., 1994). This French-community model offers the possibility of a wide range of options and so can be easily used by climotologists external to the model group. The spectral truncation T42 corresponding to a 64 -lat $\times 128$ long grid was chosen.

Each experiment was composed of runs of 50 days in an evolutive mode: approximately the first 20 days were to forget the initial atmospheric conditions, and only the results of the last 31 days (August) are considered meaningful. Still, as AGCMs are usually very sensitive to initial conditions (Palmer and Anderson, 1994) we performed three integrations for each SST field starting with different initial atmospheric conditions in the middle of July 1979, 1980 and 1981 . The preliminary analyses concern monthly means and variances for selected climatological fields for each SST pattern. They are first compared to the August climatology of the AGCM, which is actually the atmospheric model intercomparison project (AMIP) 1979-1988 (see Gates, 1992). Students' $t$-tests allow us to estimate whether the prescribed anomalies do have any significant impact on the simulation results.

\section{Results}

The main impact of these SSTA forcings concerns the dynamical and hydrological components of the climate system, especially in the tropics. This will be illustrated with five basic fields: the total (solid and liquid) precipitation anomaly field (Fig. 5), the zonal wind at $200 \mathrm{hPa}$ for documenting the tropical easterly jet (TEJ) - a planetaryscale signal associated with the northern summer monsoon (Fig. 6); zonal and meridional 850-hPa winds (Figs. 7 and 8 ) and 850 -hPa specific humidity anomalies (Fig. 9) to investigate low-level West African monsoon circulation.

As all simulations performed were based on theoretical (idealized) rather than observed SSTA fields, AMIP 1979-88 results are considered a reference for calculating anomalies and significance levels. Special attention is given to West African monsoon anomalies, and the opposition between Sahel and Guinean coast [see Janicot (1992) and Moron (1994) for the West African rainfall regionalizations] in particular is investigated. Note also that this particular reference period is anomalously dry over the Sahelian belt (relative to 30 - or 50-year normals).

\subsection{Precipitations}

Before considering results of different forcings, an overview of the model climatology should be made in order to establish limits of the model's is skill at reproducing reality. This was extensively described in Déqué et al. (1994), so that we present here only the total precipitation field: one of the most difficult to simulate and very sensitive to the subgrid parametrization scheme. Figure 4 presents the 10-year AMIP mean for August. The monsoon rainfall is quite well represented in terms of its amount and spatial extension. East coast and subtropical deserts are simulated. However, systematical biases exist, such as the overly small northward extension of the Indian monsoon, 
which experiences its largest amounts south of the continent, and the overestimation of the precipitation over Sahara (see Déqué et al., 1994).

Figure 5 represents different precipitation anomalies regarding AMIP results. Areas of anomalies significant at the $5 \%$ confidence level are shaded. Atl $+/-$ (Fig. 5a), as expected, exhibits a strong local north-south anomaly gradient over the tropical Atlantic, with positive anomalies extending towards West Sahel. Atl $-/+$ (Fig. 5b) produces reverse quasi-symmetrical anomalies

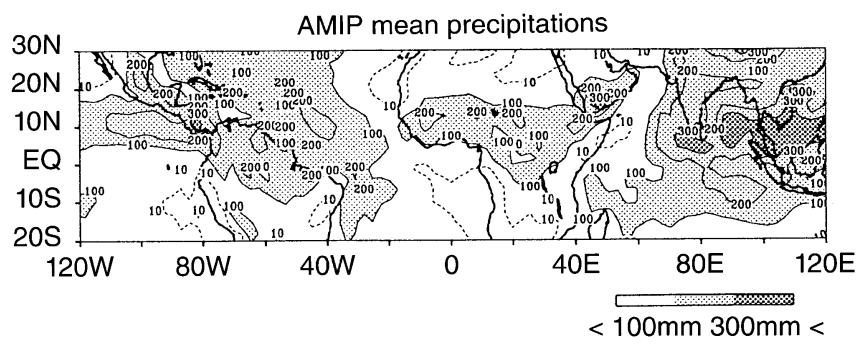

Fig. 4. AMIP 1979-1988 monthly mean precipitations for August. Solid lines every $100 \mathrm{~mm}$ per month; dashed line for the $10 \mathrm{~mm}$ per month level. Shaded areas: light grey for $100-300 \mathrm{~mm}$ per month, dark grey beyond $300 \mathrm{~mm}$ per month (with regard to ATL $+/-$ ) over the Atlantic Ocean and Arabian Sea. The sole ATL forcing seems not to be able to produce significant rainfall anomalies over West Africa (relative to the AMIP mean).

Global-mode combinations lead to positive significant anomalies in the eastern and central Pacific due to ENSOlike anomalies of the $\mathrm{T}(\mathrm{GTm})$ mode. The impact of $\mathrm{T}-\mathrm{E}$ (Fig. 5c) on Sahel rainfall is not significant except for the negative anomalies over West Sahel. The maximum of the Indian monsoon is partly concerned with positive anomalies, while anomalies are negative over the continent. $\mathrm{T}+\mathrm{E}$ (Fig. 5d) exhibits the same anomaly pattern except for its magnitude and significance level, which are larger over the tropical Atlantic Ocean and the Sahel, in coherence with the major rainfall decrease observed during the 1976-1993 period when anomalously warm conditions over the central and eastern Pacific were embedded in the warmer than long-term mean southern hemisphere. In the Indian Ocean the significant anomaly area is more extended.

The superimposed local ATL $+/-$ anomalies (Fig. 5e, f) lead to the reduction of the Sahelian deficit of $\mathrm{T}-\mathrm{E}$ and $\mathrm{T}+\mathrm{E}$, especially over the Atlantic Sahel. Large Sahelian and Saharan deficits of the $\mathrm{T}+\mathrm{E}$ vanish in $\mathrm{T}+\mathrm{E} \& \mathrm{ATL}+/-$. Indian monsoon anomalies are less extended southwards.
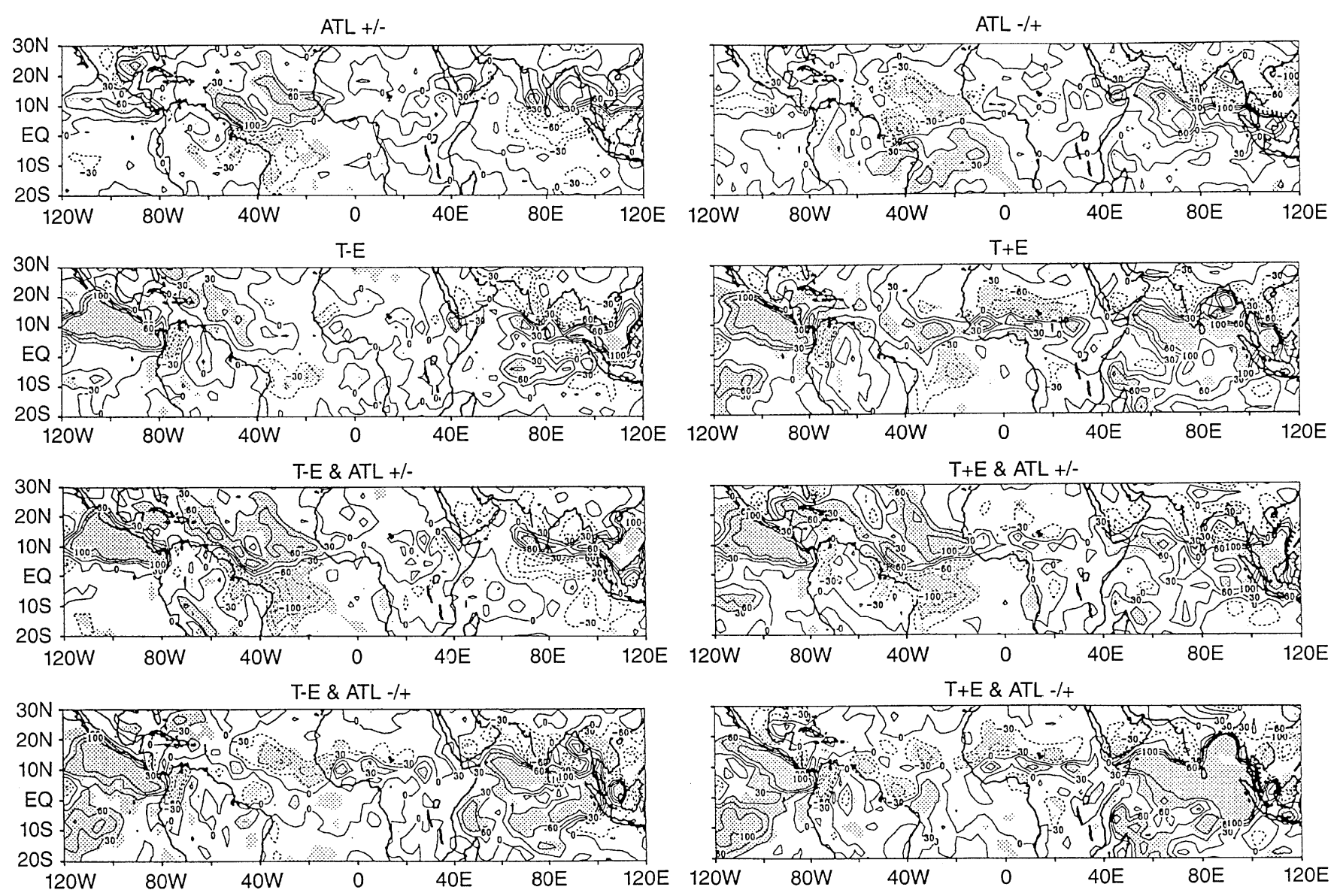

Fig. 5. Total precipitation monthly mean anomalies in regard to AMIP results. Positive (resp. negative) anomaly levels at 0, 30, 60,

$100 \mathrm{~mm}$ per month (resp. $-30,-60,-100)$ in solid (resp. dashed) line. Anomaly areas significant at the $5 \%$ level are shaded 
ATL $-/+$ reinforces $\mathrm{T}-\mathrm{E}$ anomalies (Fig. $5 \mathrm{~g}$ ): the Guinean coast exhibits large, partly significant positive anomalies and the Sahelian region experiences larger negative anomalies, unlike in the $\mathrm{T}+\mathrm{E} \& \mathrm{ATL}-/+$ (Fig. 5h), where ATL $-/+$ does not much influence the large T + E (Fig. 5d) anomalies. The Indian monsoon is globally and significantly reinforced over the Indian Ocean and the Bay of Bengal.

The model takes into account the imposed SSTAs and seems to simulate accurately precipitation anomalies leading, in extreme cases, to severe deficits over Sahel and excess over the Guinean coast, producing dipolar anomaly patterns (Janicot, 1992; Moron, 1994). The reverse of the Atlantic anomalies greatly weakens negative anomalies over Sahel mainly during $\mathrm{T}-\mathrm{E}$ (almost corresponding to the pre-1970 records). This skill to simulate rainfall anomalies cannot occur without coherent anomalies in some other fields.

\subsection{0-hPa zonal wind}

The main characteristic of this flow is the TEJ, a planetary-scale signal of northern monsoon. Figure 6 shows global raw field with shaded light (dark) areas of significant positive (negative) anomalies in regard to AMIP mean. The TEJ is quite well simulated and strong differences can be distinguished between experiments.

ATL $+/-$ (Fig. 6a) leads to a significant strengthening of the TEJ, which attains a velocity of $-12 \mathrm{~m} / \mathrm{s}$ over Africa and reaches Central America. Significant acceleration can be noticed over the north of South America. Moreover, its meridional extend reaches $0^{\circ}$ latitude. The ATL - / + TEJ (Fig. 6b) is much less strong, with a velocity of only $-8 \mathrm{~m} / \mathrm{s}$ at its core over West Africa. Its velocity experiences significant positive anomalies (weakening) west of $40^{\circ} \mathrm{W}$ and in its West African and Indian axes.

All subsequent analyses including global forcing of the warm phase of ENSO involve a more or less significant decrease in TEJ from South Asia to Africa, corresponding to the modelling study of Palmer et al. (1992) and diagnostic results of Moron et al. (1995b). T - E (Fig. 6c) leads to a less zonally and meridionally extended TEJ over the monsoon area, with significantly diminished velocity on its north and south margins, but also in its axis from India to the horn of Africa. T + E (Fig. 6d) simulates a less extended and less rapid TEJ with the $-8 \mathrm{~m} / \mathrm{s}$ core reaching only the central Sahel. Positive significant anomalies are displayed on its southern and western limits.

The ATL + $/-$ additional effect relative to globalmodes forcing is a strengthening of the TEJ. T-E\&
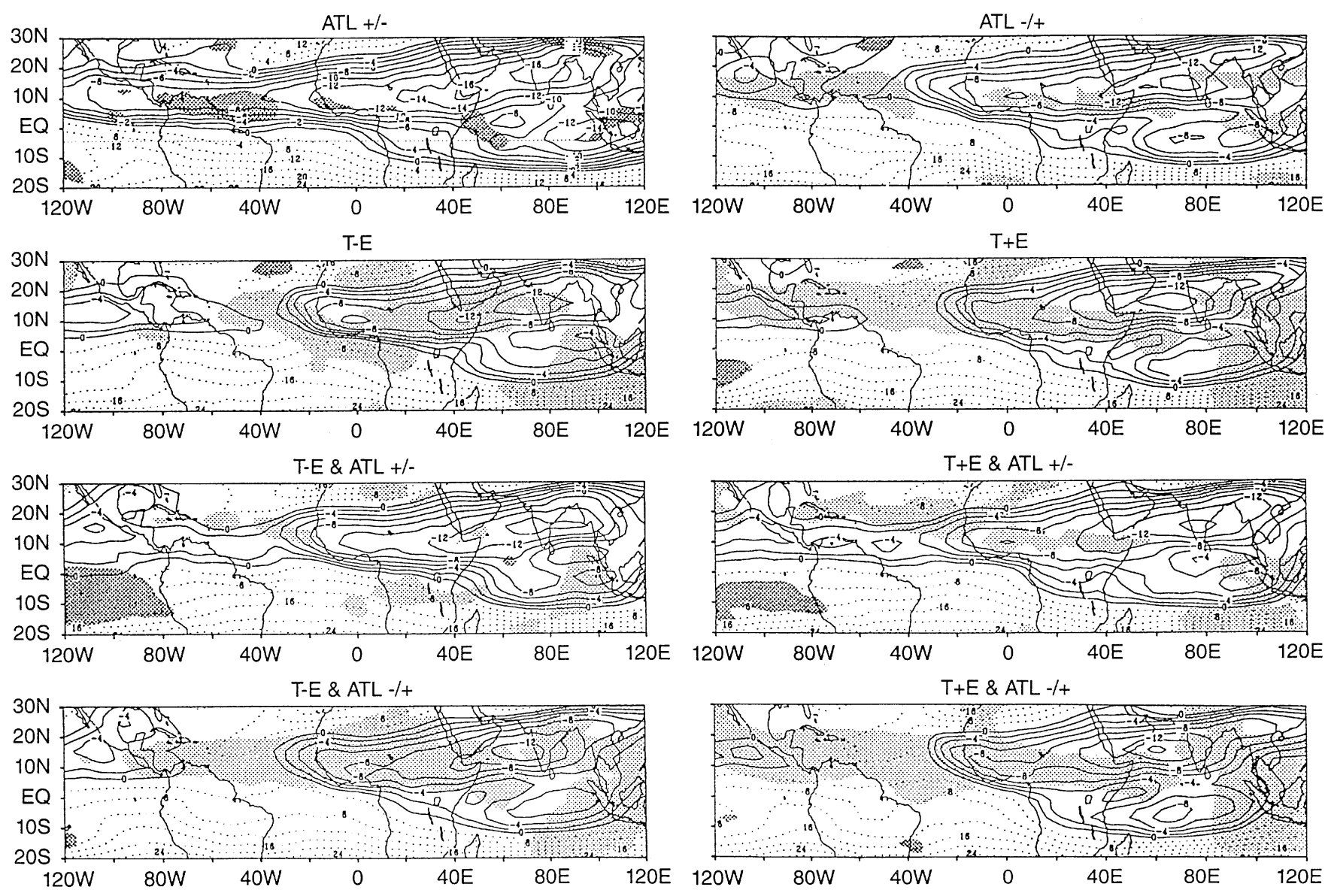

Fig. 6. Zonal wind component at $200 \mathrm{hPa}$. Solid (dotted) lines for negative-easterly (positive-westerly) values, every $2 \mathrm{~m} / \mathrm{s}(4 \mathrm{~m} / \mathrm{s})$. Pos-

itive (negative) anomaly areas significant at the $5 \%$ level are shaded in light (dark) grey 
ATL $+/-$ (Fig. 6e) exhibits greater zonal and meridional extents of the TEJ and an increase of the core velocity $(-10 \mathrm{~m} / \mathrm{s}) . \mathrm{T}+\mathrm{E} \& \mathrm{ATL}+/-$ (Fig. 6f ) experiences an enhancement of the zonal extent of the jet and its core $(-8 \mathrm{~m} / \mathrm{s}$ over the whole West African area). Anomalies relative to AMIP concern west margins of the high-velocity axis for $\mathrm{T}-\mathrm{E} \& \mathrm{ATL}+/-$, north margin and the core of the $\mathrm{T}+\mathrm{E} \& \mathrm{ATL}+/-$ forcing.

ATL $-/+$ produces especially a slowing down of the TEJ axis for the T - E\& ATL - / + (Fig. 6g) when compared to $\mathrm{T}-\mathrm{E}$, and the whole jet area is concerned with significant positive anomalies. T $+\mathrm{E} \& \mathrm{ATL}-/+$ (Fig. 6h) exhibits a reinforced core (with regard to $\mathrm{T}+\mathrm{E}$ ) but its zonal and meridional extents remain the same. Positive significant anomalies remain over the Atlantic and Africa.

As for the precipitation fields, the model simulates accurately expected anomalies and the impact of the SSTAs are largely significant. Local Atlantic anomalies interfere with global anomalies and reduce/reinforce TEJ anomalies.

\subsection{Low-level fields}

This section deals with $850-\mathrm{hPa}$ wind and specific humidity and focusses on the local West African monsoon area to investigate impacts of different forcings at the regional scale. $850 \mathrm{hPa}$ was the lowest AMIP level available and was necessary to compare forcing results with the internal atmospheric variability. Figure 7 shows the zonal $850-\mathrm{hPa}$ wind component with significant anomaly areas shaded. Monsoon westerly flow is simulated in all experiments but to a varying extent. ATL $+/-$ (Fig. 7a) exhibits the largest zonal and meridional extension and the highest velocity in the core. It also leads to a reduction of the easterly
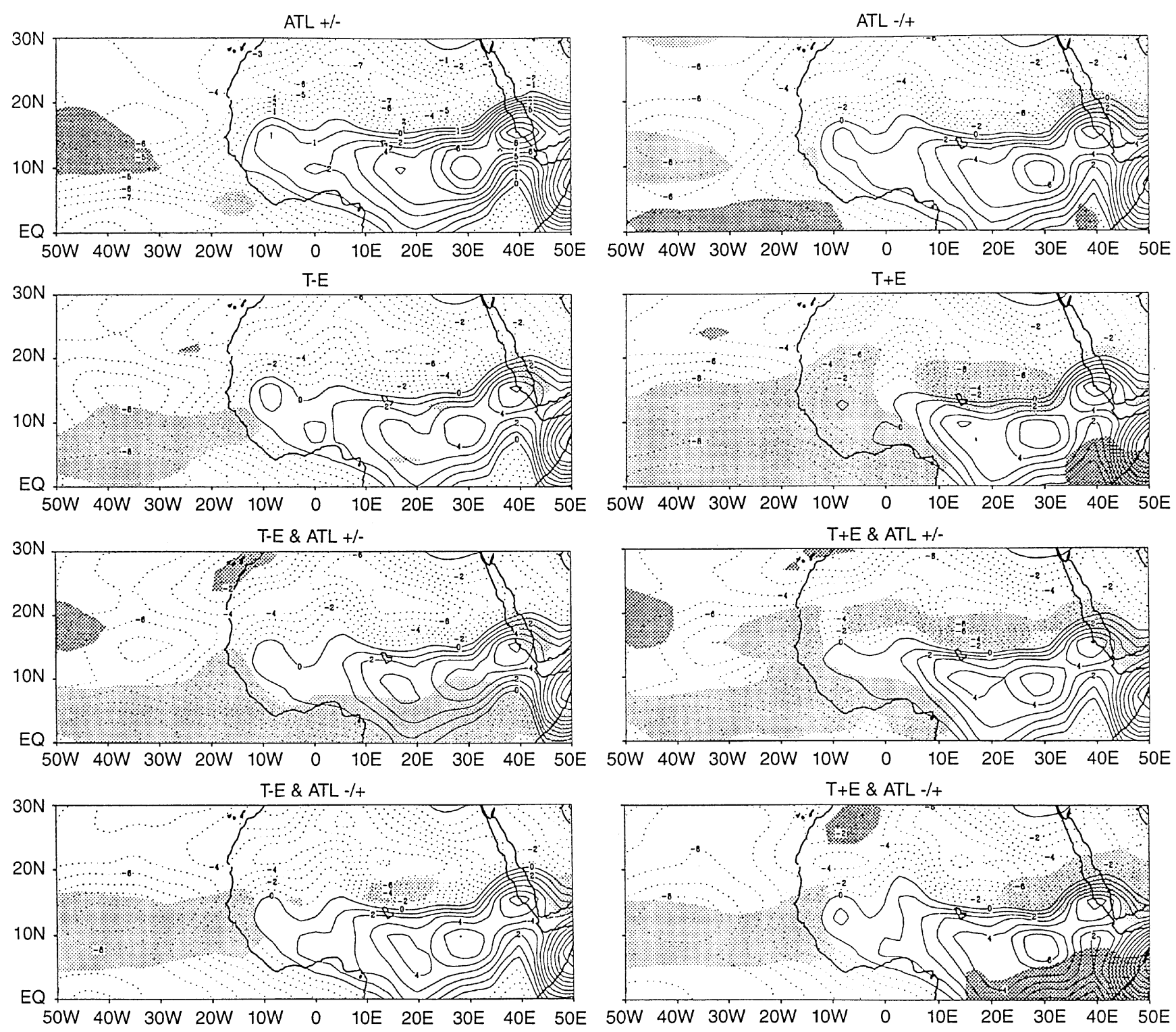

Fig. 7. Zonal wind component at $850 \mathrm{hPa}$. Positive/negative values in solid (dotted) line every $1 \mathrm{~m} / \mathrm{s}$. Negative (positive) anomaly areas significant at $5 \%$ are shaded in light (dark) grey 
flow over the Atlantic. ATL -/+ (Fig. 7b) has approximately the same scheme except for the highest velocity and less westward-extended $2 \mathrm{~m} / \mathrm{s}$ area. It shows also an enhancement of the North Atlantic easterlies but a weakening over equatorial Atlantic, something also found by Wagner and Da Silva (1994).

T - E (Fig. 7c) monsoon flow has less westward extent and has slower maxima at its core. It produces a significant enhancement of easterly flows over the Atlantic from $0^{\circ}$ to $10^{\circ} \mathrm{N}$. T $+\mathrm{E}$ (Fig. 7d) westerly flow has smaller zonal extent, hardly reaching $0^{\circ}$, but its core velocity is higher than that of the T-E. Easterly flows are largely enhanced west of the $0^{\circ}$ and north of $15^{\circ}$ over the Sahel. East Africa experiences enhanced westerly flows, probably related to warm SSTAs over the Indian Ocean.

$\mathrm{ATL}+/$ - influences significantly the T $-\mathrm{E}$ monsoon flow (Fig. 7e) on its southern margins where westerly (easterly) winds are slowed (enhanced). In the
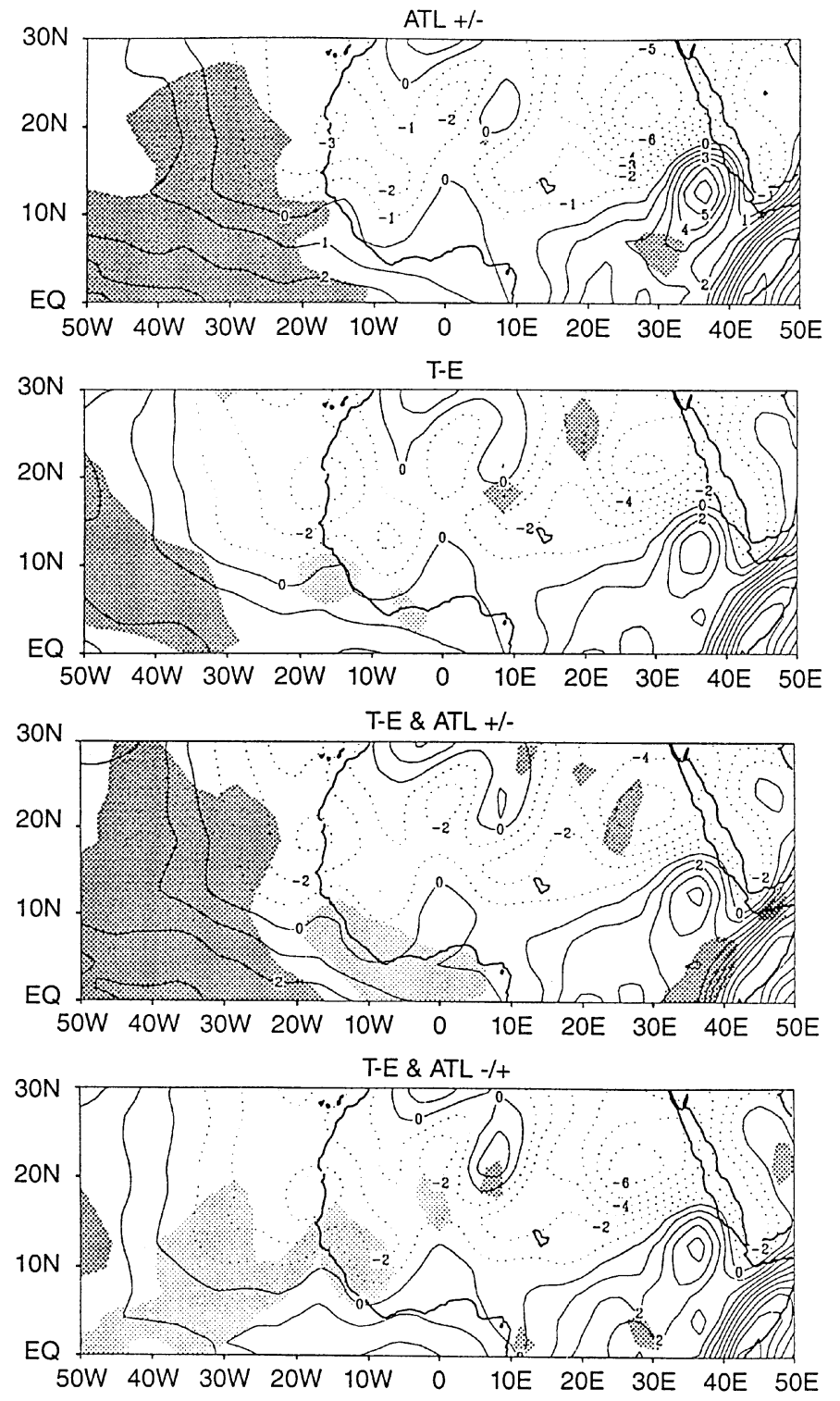

$\mathrm{T}+\mathrm{E} \& \mathrm{ATL}+/-$ (Fig. 7f), easterly anomalies still affect Atlantic Ocean $\left(0^{\circ}\right.$ to $\left.10^{\circ} \mathrm{N}\right)$, West African coast and southern Saharan margins north of $15^{\circ} \mathrm{N}$. The superimposition of ATL $-/+$ (Fig. 7g, h) produces a westward extension of the low-level westerly flow and reduces easterly anomalies south of $5^{\circ} \mathrm{N}$. The Atlantic Ocean and African coast experience significantly enhanced easterly flows.

Figure 8 shows the meridional component of the 850$\mathrm{hPa}$ flow and significant anomalies. Southerly flows are mainly located over the Atlantic Ocean and there are quite large differences in their land extent. ATL + / (Fig. 8a) exhibits the more northward migration of the monsoon flow over a large oceanic area. It is also concerned with the strongest gradient in the northerly and southerly fluxes. This gradient is weaker in the ATL $-/+$ (Fig. 8b) experiments, and undergoes a further weakening of the northern extension of monsoon flux over the
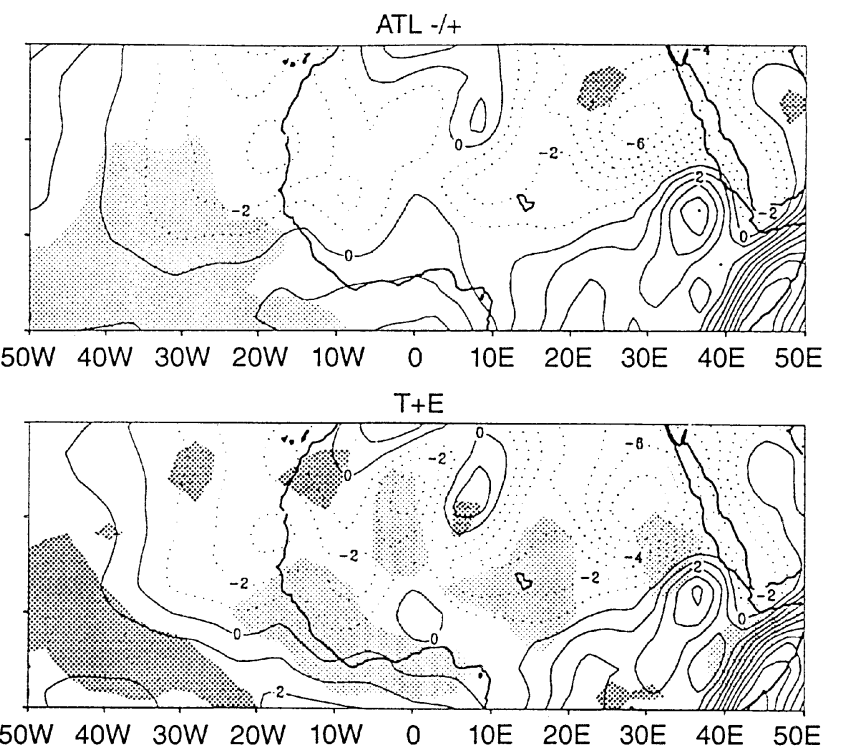

50W 40W 30W 20W 10W O 10E 20E 30E 40E 50E
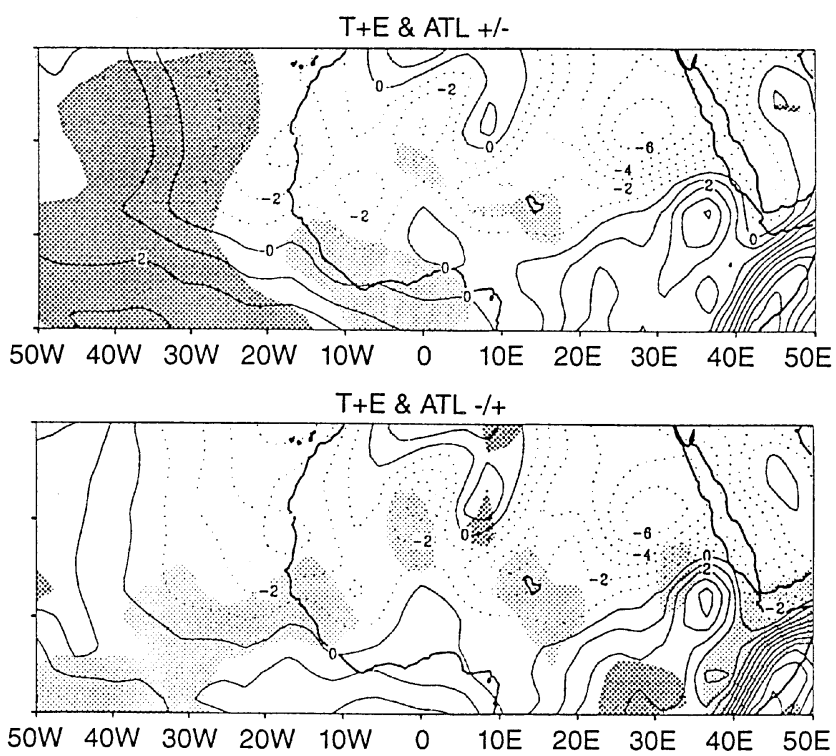

Fig. 8. Same as for Fig. 7 except for the meridional wind component at $850 \mathrm{hPa}$ 
Atlantic Ocean. In general, global modes induce a less northward extension of southerly wind. Their patterns (Fig. 8c, d) show main positive anomalies over the Ocean west of $30^{\circ} \mathrm{W}$ and negative anomalies over the Guinean coast. The latest are particularly extended in the $\mathrm{T}+\mathrm{E}$ (Fig. 8d) experiment. This experiment also shows strong flux velocity gradient. These Guinean coast anomalies are not modified by the ATL $+/-$ superimposition, and both T $-\mathrm{E} \& \mathrm{ATL}+/-$ (Fig. 8e) and T $+\mathrm{E} \& \mathrm{ATL}+/-$ (Fig. 8f) exhibit about the same flow and anomaly patterns with negative anomalies over the Guinean coast area and positive over the Atlantic Ocean west of $20^{\circ} \mathrm{W}$. ATL $-/+$ modifies in both cases (Fig. 8g, h) the Guinean coast anomalies and leads to a lesser northern extension of the monsoon flows over the Atlantic.

Figure 9 shows $850-\mathrm{hPa}$ specific humidity anomalies in regard to AMIP results. Significant anomalies are shaded.
There is a quasi-symmetric reversed significant anomaly pattern over the Atlantic Ocean in the ATL +/(Fig. 9a) and ATL $-/+$ (Fig. 9b) forcings. Global modes (Fig. 9c, d) provide more anomalies over the continent: positive over western parts of the Guinean coast and particularly strong negative ones north of $10^{\circ} \mathrm{N}$ in the $\mathrm{T}+\mathrm{E}$ experiment. The Guinean coast anomalies strengthen in the $\mathrm{T}-\mathrm{E} \& \mathrm{ATL}+/-$ (Fig. 9e) and $\mathrm{T}+\mathrm{E} \& \mathrm{ATL}+/-\quad$ (Fig. 9f) forcings, and there is a weakening of the $\mathrm{T}+\mathrm{E}$ negative anomalies. The Atlantic Ocean is concerned with positive anomalies in both forcings. ATL $-/+$ superimpositions lead to enhanced negative anomalies in the $\mathrm{T}-\mathrm{E} \& \mathrm{ATL}-/+$ (Fig. 9g) case [when compared to the $\mathrm{T}-\mathrm{E}$ experiment (Fig. 9c)] and to negative anomalies which are less strong in their core but more zonally extended for the $\mathrm{T}+\mathrm{E} \&$ ATL $-/+$ (Fig. 9h) pattern. Both exhibit fairly zonal
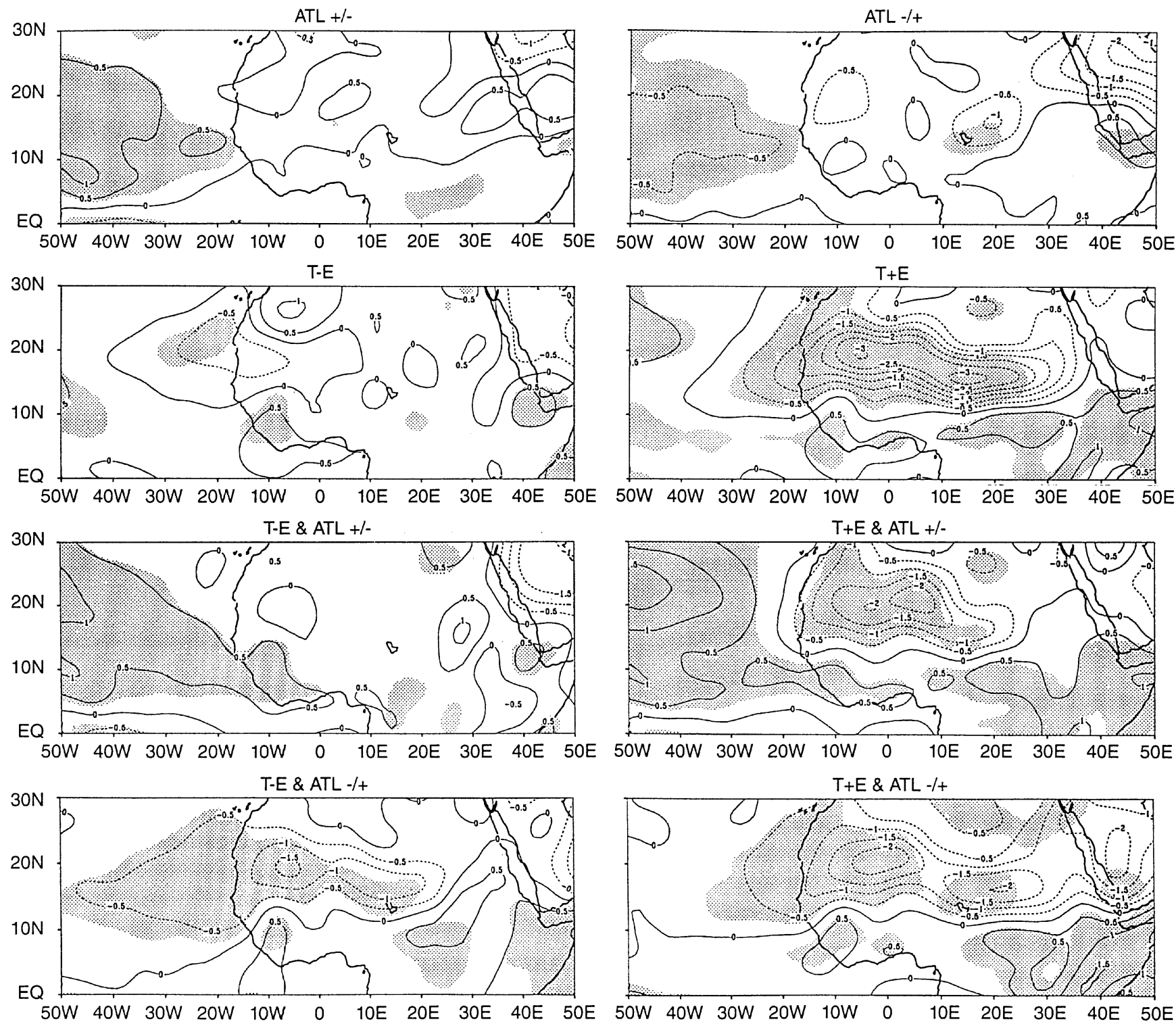

Fig. 9. Specific humidity anomalies at $850 \mathrm{hPa}$. Positive (negative) anomalies in solid (dashed) line every $0.5 \mathrm{~g} / \mathrm{kg}$. Areas significant at the $5 \%$ level are shaded 
anomaly patterns with positive anomalies south of $12^{\circ} \mathrm{N}$ and negative north of this limit.

\section{Discussion and concluding remarks}

An attempt is made to investigate the role of interhemispheric and Atlantic thermal gradient on ENSO warmphase global and regional-scale forcing. Eight experiments of $3 \times 50$-day runs were performed on the ARPEGEClimat AGCM by prescribing specific boundary conditions from composite and multivariate analyses. Results are tested relative to the AMIP experiment. The main results are summarized below:

- Global forcing, including warm phase of ENSO and relative positive (resp. negative) anomalies in southern hemisphere, particularly over the Indian Ocean (resp. northern hemisphere, particularly in the North Atlantic) (experiment $\mathrm{T}+\mathrm{E}$ ), in coherence with observed SSTA after 1970, involves a significant decrease in monsoon dynamic at global and regional scales by weakening TEJ from southern Asia to northern South America, and reducing low-level monsoon flow over northern tropical Africa. This result is consistent with diagnostic results of Fontaine et al. (1995), Moron et al. (1995a, b), Janicot et al. (1996), but also with modelling studies of Palmer et al. (1992).

- When the warm phase of ENSO is combined with an inversed global SSTA pattern (experiment T - E) the response is less significant (particularly on rainfall fields over Atlantic and Indian regions), demonstrating that ENSO could not be investigated as an isolated phenomenon independent of the global thermal context. It seems that impact of ENSO events is strongest when the southern hemisphere (in particular the Indian Ocean) is warmer than the long-term mean and when the northern hemisphere is colder, suggesting an austral summer pattern. This result, also reported by Wang and Ropelewski (1995), needs further investigation.

- Addition of Atlantic SSTAs also leads to interesting results: the sole Atlantic forcing (experiments ATL +/and ATL $-/+)$ is unable to force significant anomalies (relative to the AMIP mean) on bordering continents, but the combination with global forcing (experiments $\mathrm{T}-\mathrm{E} \& \mathrm{ATL}+/-, \quad \mathrm{T}+\mathrm{E} \& \mathrm{ATL}-/+$, $\mathrm{T}-\mathrm{E} \& \mathrm{ATL}-/+$ and $\mathrm{T}+\mathrm{E} \& \mathrm{ATL}+/-$ ) leads to a significant modulation of the climatic signal over northern tropical Africa and near Atlantic. The inclusion of $\mathrm{ATL}+/-$ reduces significantly the impact of ENSO forcing, especially during T $-\mathrm{E}$. It could be associated with the weak observed impact of ENSO events before 1970 (Moron et al., 1995a; Janicot et al., 1996). This modulation is strong for rainfall fields over northern tropical Africa, but also on low-level relative humidity and TEJ velocity. ATL $-/+$ forcing is in general of the same sign as $\mathrm{T}-\mathrm{E}$ and, mainly, $\mathrm{T}+\mathrm{E}$ forcing and it could reinforce several climatic signals, such as the dryness over the Sahelian area.

These preliminary results state clearly that remote teleconnexions of ENSO warm phase are significantly modulated by the global polarity of large-scale and
Atlantic thermal state. In future studies, we propose to investigate more precisely the dynamical features of each experiment and comparisons between them.

Acknowledgements. The authors thank the CNRM (Météo-France, Toulouse) staff and especially M. Déqué for kindly allowing the use of the ARPEGE-Climat AGCM.

The Editor in Chief thanks S. Janicot for his help in evaluating this paper.

\section{References}

Bottomley, M., C. K. Folland, J. Hsiung, R. E. Newell, and D. E. Parker, Global Ocean Surface Temperature, Met. Office, Bracknell, 313 plates and 20 pages, 1990.

Camberlin, P., June-September rainfall in North-Eastern Africa and atmospheric signals over the tropics: a zonal perspective, Int. J. Climatol., 15, 773-783, 1995.

Déqué, M., C. Dreveton, A. Braun, and D. Cariolle, The ARPEGE/ IFS atmosphere model: a contribution to the French community climate modelling, Clim. Dyn., 10, 249-266, 1994.

Deser, C., and M. L. Blackmon, Surface climate variations over the North Atlantic Ocean during winter: 1900-1989, J. Clim., 6, 1743-1753, 1996.

Diedhiou, A., and J. F. Mahfouf, Comparative influence of land and sea surfaces on the Sahelian drought: a numerical study, Ann. Geophysicae, 14, 115-130, 1996.

Druyan, L. M., The sensitivity of sub-Saharan precipitation to Atlantic SST, Clim. Change, 18, 17-36, 1991.

Folland, C. K., T. N. Palmer, and D. E. Parker, Sahel rainfall and worldwide sea temperature 1901-1985, Nature, 320, 602-607, 1986.

Folland, C. K., R. W. Reynolds, M. Gordon, and D. E. Parker, A study of 6 operational SST analyses, J. Clim., 6, 96-113, 1993.

Fontaine, B., and S. Bigot, West African rainfall deficits and sea surface temperatures, Int. J. Climatol., 11, 271-286, 1993.

Fontaine, B., S. Janicot, and V. Moron, Rainfall anomaly patterns and wind field signals over West Africa in August (1958-1989), J. Clim., 8, 1503-1508, 1995.

Gates, W. L., The atmospheric model intercomparison project, Bull. Am. Meteorol. Sci., 73, 1962-1970, 1992.

Gill, A. E., Some simple solutions for heat budget induced tropical circulation, Q. J. Roy. Meteorol. Soc., 106, 447-462, 1980.

Hastenrath, S., Interannual variability and annual cycle: mechanisms of circulation and climate in the tropical Atlantic sector, Mon. Weather Rev., 112, 1097-1107, 1984.

Hastenrath, S., Climate dynamics of the tropics, Kluwer, Dodrecht, 1991.

Hastenrath, S., and L. Heller, Dynamics of climatic hazards in Northeast Brazil, Q. J. Roy. Meteorol. Soc., 103, 77-92, 1977.

Hastenrath, S., and A. Covey, The Pacific El-Niño phenomenon and the Atlantic circulation, Q. J. Roy. Meteorol Soc., 110, 411-425, 1978.

Janicot, S., Spatio-temporal variability of West African rainfall; Part II: Associated surface mass characteristics, J. Clim., 5, 499-511, 1992.

Janicot, S., V. Moron, and B. Fontaine, Sahel droughts and ENSO dynamics, Geophys. Res. Lett., 23, 515-518, 1996.

Kawamura, R., A rotated EOF analysis of global SST variability with interannual and interdecadal scales, J. Phys. Oceanogr., 24, 707-715, 1994.

Kushnir, Y., Interdecadal variations in North Atlantic SST and associated atmospheric conditions, J. Clim., 7, 141-157, 1994.

Lamb, P. J., Case studies of tropical Atlantic surface circulation patterns during recent sub-Saharan weather anomalies: 1967 and 1968, Mon. Weather Rev., 106, 482-491, 1978a.

Lamb, P. J., Large-scale tropical Atlantic surface circulation pattern associated with sub-Saharan weather anomalies, Tellus, 30A, 240-251, 1978 b.

Lough, J. M., Tropical Atlantic SST and rainfall variations in sub-Saharan Africa, Mon. Weather Rev., 114, 561-570, 1986. 
Markham, C. G., and D. R. McLain, Sea surface temperature related to rain in Ceara, Northeastern Brazil, Nature, 265, 320-323, 1977.

Mehta, V. M., and T. Delworth, Decadal variability in the Tropical Atlantic ocean surface temperature in shipboard measurements and in global ocean atmosphere model, J. Clim., 8, 172-190, 1995.

Moron, V., Guinean and Sahelian rainfall anomaly indices at annual and monthly scales (1933-1990), Int. J. Climatol., 12, 325-341, 1994.

Moron, V., S. Bigot, and P. Roucou, Rainfall variability in subequatorial America and Africa and relationships with the main SST modes (1951-1990), Int. J. Climatol., 15, 1297-1322, 1995a.

Moron, V., B. Fontaine, and P. Roucou, Global equatorial variability of 850- and 200-hPa zonal winds from rawinsondes between 1963 and 1989, Geophys. Res. Lett, 22, 1701-1704, 1995b.

Moura, A. D., and J. Shukla, On the dynamics of droughts in NorthEast Brazil: observations, theory and numerical experiments with a general circulation model, J. Atmos. Sci., 38, 2653-2675, 1981.

Nicholls, N., The southern oscillation and Indonesian sea surface temperatures, Mon. Weather Rev., 112, 42-43, 1984.

O'Lenic, E. A., and R. E. Livezey, Practical considerations in the use of rotated principal components analysis in diagnostic studies of upper height fields, Mon. Weather Rev., 116, 1682-1689, 1988.

Palmer, T. N., The influence of the Atlantic, Pacific and Indian Oceans on Sahel rainfall, Nature, 322, 251-253, 1986.

Palmer, T. N., and D. L. T. Anderson, The prospects for seasonal forecasting - a review paper, Q. J. Roy. Meteorol. Soc., 112, 613-638, 1994.

Palmer, T. N., C. Brankovic, P. Viterbo, and M. J. Miller, Modelling interannual variations of summer monsoons, J. Clim., 5, 399-417, 1992.

Parker, D. E., P. D. Jones, C. K. Folland, and A. Bevan, Interdecadal changes of surface temperature since the late nineteenth century, J. Geophys. Res., 99, 14373-14399, 1994.

Rasmusson, E. M., and T. H. Carpenter, Variations in tropical sea surface temperature and surface wind fields associated with the
Southern Oscillation/EL-Niño, Mon. Weather Rev., 110, 355-384, 1982.

Richman, M. B., Rotation of principal components, Int. J. Climatol., 6, 293-336, 1986.

Ropelewski, C. F., and M. S. Halpert, Global and regional scale precipitation and temperature patterns associated with El Niño/Southern Oscillation, Mon. Weather Rev., 115, 1606-1626, 1987.

Roucou, P., J. O. R. de Aragão, A. Harzallah, B. Fontaine, and S. Janicot, Vertical motion changes related to Northeast Brazil rainfall variability: AGCM simulation, Int. J. Climatol., in press, 1996.

Rowell, D. P., C. K. Folland, K. Maskell, and N. Ward, Variability of summer rainfall over tropical North Africa (1906-1992); observations and modelling, Q. J. Roy. Meteorol. Soc., 113, 669-704, 1995.

Shinoda, M., and R. Kawamura, Tropical rainbelt, circulation and SST associated with Sahelian rainfall trend, J. Meteorol. Soc. Japan, 72, 1233-1247, 1994.

Shukla, J., Interannual variability of Monsoons, in Monsoons, eds. Fein and Stephens, Wiley, New York, 399-464, 1987.

Shukla, J., and M. J. Fenessy, Prediction of time-mean atmospheric circulation and rainfall: influence of Pacific sea surface temperature anomaly, J. Atmos. Sci., 45, 9-28, 1988.

Tanaka, M., B. W. Weare, A. R. Navato, and R. E. Newell, Recent African rainfall pattern, Nature, 255, 201-203, 1975.

Wagner, R. G., and A. M. Da Silva, Surface conditions associated with anomalous rainfall in the Guinean coastal region, Int. J. Climatol., 14, 179-199, 1994.

Wang, B., and C. F. Ropelewski, An assessment of ENSO-scale secular variability, J. Clim., 8, 1584-1599, 1995.

Ward, N. M., and C. K. Folland, Prediction of seasonal rainfall in the north Nordeste of Brazil using eigenvectors of sea surface temperature, Int. J. Climatol., 11, 711-743, 1991.

Ward, N. M., C. K. Folland, K. Maskell, A. W. Colman, D. P. Rowell, and K. B. Lane, Experimental seasonal forecasting of tropical rainfall at the UK Meterological Office, in Prediction of Interannual Climate Variations, NATO ASI Series, Vol. 16, SpringerVerlag, Berlin Heidelberg, 197-216, 1993. 